\title{
KASUS WANG RENSHU: SEBUAH KEGAGALAN DIPLOMASI RRC TERHADAP INDONESIA
}

\author{
Tuty Enoch Muas
}

\begin{abstract}
The Chinese-Indonesian relations in 1951 was in tension due the actions of Ambassador Wang Renshu. As China was not favored in the international arena for its communist stand, the Chinese citizens in Indonesia became important factor in the relations between China and Indonesia where they were divided into taking side with either the communists or the capitalists. Wang Renshu, a senior member in the China Communist Party, has recruited between six and seven hundred thousand Indonesians of Chinese ancestry to adopt Chinese citizenship, of which it became a threat to the Chinese-Indonesian diplomatic relations. The withdrawal of Ambassador Wang Renshu marked the failure of the ChineseIndonesian diplomatic relations.
\end{abstract}

\section{Keywords}

Wang Renshu, Indonesia's position, diplomatic failure.

\begin{abstract}
Abstrak
Tulisan ini mengangkat hubungan Cina-Indonesia yang menegangkan di tahun 1951 yang dipicu oleh tindakan duta besar Cina di Indonesia, Wang Renshu. Cina di dunia internasional pada waktu itu kurang mendapat dukungan karena posisinya sebagai negara komunis. Dalam situasi ini, warga Tionghoa di Indonesia menjadi penting dalam hubungan diplomasi Cina-Indonesia karena posisi Indonesia terbagi di antara kekuatan sosialis dan kapitalis. Wang Renshu, seorang anggota senior Partai Komunis Cina telah menarik sekitar 600-700 ribu warga Tionghoa di Indonesia menolak kewarganegaraan Indonesia, yang mengakibatkan posisi Indonesia terancam. Putusnya hubungan diplomatik dengan Cina pada masa itu ditandai dengan ditariknya Wang Renshu dan menjadi tanda kegagalan hubungan diplomatik antara Cina dan Indonesia.
\end{abstract}

\section{Kata kunci}

Wang Renshu, posisi Indonesia, kegagalan diplomatik.

\section{PENDAHULUAN}

Republik Rakyat Cina (RRC - Zhonghua Renmin Gongheguo) berdiri pada tanggal 1 Oktober 1949, setelah Partai Komunis Cina (PKC - Gongchandang) mengalahkan rejim Partai Nasionalis Cina (PNC-Guomindang) yang saat itu menguasai pemerintahan Republik Cina (Zhonghua Minguo). ${ }^{1}$ Presiden Chiang Kaishek yang juga merupakan

${ }^{1}$ Dalam sejarah PKC/RRC perang melawan PNCdisebut sebagai Renmin jiefang zhanzheng (人民解放战争) 
pemimpin PNC waktu itu, karena terdesak kemudian membawa sisa-sisa kekuatannya ke pulau Taiwan. PNC dengan bantuan dari Amerika Serikat melanjutkan pemerintahan Republik Cina di pulau tersebut. Bertahannya Republik Cina di Taiwan menyebabkan RRC masih harus bertarung untuk mendapatkan pengakuan internasional, khususnya di forum Perserikatan Bangsa-Bangsa (PBB) yang tetap mengakui keanggotaan Republik Cina. RRC menolak adanya dua perwakilan Cina di forum internasional. Oleh karena itu cita-cita menyatukan Taiwan ke dalam wilayah kedaulatannya merupakan bagian dari kepentingan nasional RRC yang terus diperjuangkan sampai sekarang.

Dalam upaya menunjukkan eksistensinya RRC beruapaya keras menjalin hubungan dengan berbagai negara di dunia dengan gayanya sendiri. Berpegang pada ideologi komunis yang berlandaskan Marxisme dan Leninisme, politik luar negeri RRC di tahap awal sangat kental diwarnai oleh sikap anti imperialisme, kolonialisme, dan kapitalisme. Sikap yang sangat pro komunis itu menyebabkan tidak mudah bagi RRC dalam mendapatkan pengakuan internasional maupun dalam menjalin hubungan bilateral. Hubungan RRC dengan Indonesia memiliki keunikan. Secara historis hubungan bangsa Cina dengan bangsa Indonesia telah melewati kurun waktu yang panjang. Menurut Kong Yuanzhi bila dilihat dari asal usul kedua bangsa, bukan mustahil ada hubungan darah di antara kedua bangsa itu. Terutama bila diyakini bahwa nenek moyang bangsa Indonesia juga berasal dari sekitar wilayah Yunnan, di Tiongkok Barat daya. ${ }^{2}$

Hubungan diplomatik RRC-RI mulai terjalin secara resmi pada tahun 1950, namun hubungan itu tidak serta merta berjalan mulus. Kasus Wang Renshu adalah salah satu contoh dari tidak mulusnya hubungan kedua negara di tahap awal. Bahkan bila dilihat dalam persfektif bahwa penunjukan Wang sebagai Duta Besar adalah bagian dari strategi RRC untuk 'menaklukkan' Indonesia, maka kasus Wang Renshu dapat disebut sebagai sebuah kegagalan. Adapun yang menjadi pokok bahasan dalam makalah ini adalah 1) apa dan bagaimana politik luar negeri RRC di tahap awal?; 2) siapakah Wang Renshu dan mengapa Wang ditunjuk sebagai duta besar pertama untuk Indonesia?; dan 3) mengapa kasus Wang dianggap sebagai sebuah kegagalan diplomasi RRC?

\section{KEBIJAKAN YI BIAN DAO DAN POSISI INTERNASIONAL RRC}

Republik Rakyat Cina terbentuk setelah Cina mengalami masa perjuangan yang seperti tidak berujung. Ketika revolusi Xinhai berhasil menggulingkan Dinasti Qing dan Sun Yatsen dinyatakan sebagai Presiden Republik Cina pada awal tahun 1912, ternyata rakyat Cina tidak segera terbebas dari penindasan bangsa sendiri maupun bangsa asing.

atau Perang Pembebasan Rakyat, yang berlangsung sejak 1946 yaitu saat pecahnya Front Persatuan ke dua yang sebelumnya dibentuk untuk melawan Jepang.

2 Kong Yuanzhi, (2005), Silang Budaya Tingkok-Indonesia, (Xie Zhiqiong, Kong Yuanzhi, Xie Yinghua, Penerjemah), Jakarta : PT. Buana Ilmu Populer, bab 1. 
Saat itu kaum 'Junfa' atau Panglima Perang merongrong, sehingga Sun Yatsen tidak bisa meneruskan jabatannya sebagai presiden Republik Cina. ${ }^{3}$ Bangsa-bangsa asing (Barat) juga tidak segera menyerahkan wilayah-wilayah konsesinya, bahkan cenderung berupaya untuk tetap mempertahankan kekuasaannya. Dengan hasil perjuangan yang seperti itu maka dikatakan bahwa, "Revolusi Xinhai memang berhasil merubah bentuk negara Cina, tapi tidak berhasil merubah nasib bangsa Cina." 4

Wusi yundong atau Gerakan 4 Mei 1919 membawa semangat perubahan yang besar bagi rakyat Cina. Dari sini berkembang pesat Marxisme dan kemudian lahir PKC pada tahun 1921. PKC berkembang dan mampu menghimpun massa, namun tidak serta merta dapat bergandengan tangan dengan PNC untuk menyelamatkan Cina. Sulitnya menyatukan kekuatan PNC dan PKC juga menjadi beban tersendiri bagi rakyat Cina. Dua kali front persatuan yang berhasil disepakati kedua belah pihak selalu mengalami kegagalan. Kegagalan front persatuan ke dua bahkan membuat keduanya semakin bersebrangan dan berujung pada perang saudara. Dalam sejarah Cina pertentangan dua kekuatan tersebut merupakan 'bagian penuh darah'.

Dengan gambaran fakta sejarah di atas maka terlihat bahwa, berdirinya RRC tidak hanya merupakan bukti kemenangan PKC atas PNC. RRC dapat juga disebut sebagai titik awal kembali bersatunya Cina di satu tangan kekuasaan yang solid, yang ternyata tetap bertahan hingga sekarang. RRC berdiri di atas puing-puing kekuasaan yang berserakan, PKC sebagai penguasa baru dapat dikatakan benar-benar harus mulai menata Cina dari titik nol. Di dalam negeri tidak banyak kekayaan tersisa yang dapat segera dijadikan sebagai modal. Demikian juga sumber daya manusianya, tidak cukup banyak personil yang dapat diandalkan untuk membangun pemerintahan yang efektif. Hubungan dengan luar negeri juga tidak mudah, apalagi saat itu suasana perang dingin semakin terasa.

Perang dingin memecah dunia ke dalam dua blok kekuatan yaitu blok Timur dan Barat. Blok Timur identik dengan Uni Sovyet dan sekutunya yang berpaham Sosialis atau Komunis. Blok Barat identik dengan Amerika Serikat dan sekutunya yang disebut juga sebagai kekuatan Kapitalis. Berhubung sebutan kapitalis sering dikonotasikan buruk, maka muncul pula istilah 'kekuatan dunia bebas' untuk menyebut blok Barat. Dalam makalah ini istilah 'Barat' digunakan untuk menunjuk kekuatan Amerika Serikat dan sekutunya. Di tahun-tahun pertama, pengakuan internasional atau negara-negara di dunia terhadap kedaulatan RRC tidak mengalir dengan lancar. Selain karena tidak semua negara mau berhubungan dengan pemerintahan yang berideologi komunis, juga karena RRC sendiri di bawah pimpinan Mao Zedong sangat berhati-hati dalam memilih

\footnotetext{
${ }^{3}$ Untuk menghindari pertumpahan darah dan kekacauan yang lebih buruk Sun Yatsen menyerahkan jabatan presiden Republik Cina kepada Yuan Shikai, yaitu seorang jenderal Dinasti Qing yang menguasai kaum Junfa di utara dan menjanjikan penyerahan kekuasaan dinasti secara penuh (Chesneaux, at.al. (1977), China From The 1911 Revolution To Liberation, New York : Pantheon Books, hlm. 7
}

4 Chesneaux, at.al. (1977), China From...bab 2 \& 3 
negara yang akan menjalin hubungan diplomatik dengannya.

Di bawah pengaruh Mao Zedong, Cina menetapkan tiga kelompok negara dengan tiga prosedur yang berbeda bagi masing-masing bila akan menjalin hubungan diplomatik dengan RRC. Ketiga kelompok itu adalah, negara-negara sosialis, kapitalis, dan imperialis. ${ }^{5}$ Pengelompokan secara hitam putih itu dilatar belakangi oleh semangat anti kolonialisme, kapitalisme, dan imperialisme yang sangat menggebu, dan kurang mempertimbangkan kesulitan yang dihadapi di lapangan. Pada praktiknya prosedur-prosedur itu banyak mengalami penyesuaian, bahkan tidak efektif sama sekali. Sedangkan secara strategis, sejak tahun 1946 Mao telah mengemukakan pemikirannya tentang pembagian kekuatan dunia, yang terangkum dalam konsep zhongjian didai atau 'zona perantara'. ${ }^{6}$ Sentimen anti imperialis itu juga tercermin dalam pedoman kebijakan luar negeri yang dirumuskan Mao Zedong, yaitu lingqi luzao atau 'nyalakan kompor lain (baru)', dan dasao ganjing wuzi zai qingke atau 'bersihkan rumah dulu, baru mengundang tamu. ${ }^{7}$

Maksud dari 'nyalakan kompor baru' adalah, sebagai penegasan bahwa RRC tidak mewarisi pemerintahan dari PNC sehingga tidak akan melanjutkan pengakuan terhadap pewakilan negara lain yang telah ada sebelumnya. RRC juga tidak akan mengakui atau melanjutkan perjanjian dengan negara lain yang disepakati oleh pemerintahan PNC. RRC akan menjalin hubungan baru dengan berbagai negara didasari prinsip yang baru. Sedangkan pedoman 'bersihkan rumah dulu, baru mengundang tamu', dimaksudkan sebagai tanda bahwa RRC tidak tergesa-gesa dalam menjalin hubungan dengan negara lain. Cina akan mengkonsolidasikan diri dulu, baru kemudian mengembangkan hubungannya dengan luar negeri. Penerapan pedoman itu menyebabkan dalam lima tahun pertama pemerintahan RRC, tidak ada jaminan terhadap hak-hak maupun keselamatan orang asing beserta aset-aset mereka di Cina, termasuk para misionaris Barat. ${ }^{8}$ Hal itu pulalah yang mengganjal proses pembukaan hubungan diplomatik RRC dengan negara-negara Barat (Eropa).

Dalam buku Mao: Kisah-Kisah yang Tak Diketahui, diungkapkan interpretasi dan latar belakang yang berbeda atas kedua pedoman tersebut. Khususnya terhadap pedoman 'bersihkan rumah dulu, baru mengundang tamu'. Dikatakan bahwa, yang dimaksudkan Mao Zedong dalam kebijakan 'bersihkan rumah' adalah membersihkan Cina dari segala

\footnotetext{
5 "The Downing of New Diplomacy", www.washington.edu/uwpress/search/chapters/LIUCHC.pdf, hlm. 6

6 Dalam konsep ini Mao membagi dunia dalam dua kubu yaitu Sosialis dan Imperialis, di antara dua kubu itu terdapat zona antara yang berisi negara-negara yang cenderung netral. Salah satu kubu harus mampu menguasai seluruh zona antara itu baru bisa menjadi adi daya tunggal di dunia.

7 另起炉灶一打扫干净屋子再请客, Huang Anyu (黄安余), (2005), 新中国外交史 (Sejarah Diplomasi Cina Baru), Beijing: 人民出版社（Penerbit Rakyat), hlm. 7 ; Chen Yi, “Stands Guard on the Bund, Shanghai Star. (31 October 2002); Zhao, Quansheng (1996), Interpreting Chinese Foreign Policy: The Micro-Macro Linkage Approach, Oxford, New York : Oxford University Press, hlm. 46.
}

8 Walker. Richard. China Under Communism. New Heaven: Yale University Press, hlm. 239. 1955. 
macam anasir yang berbau liberal dan Barat. Dengan demikian termasuk didalamnya mengusir orang Barat yang ada di Cina. Hal itu dilatarbelakangi oleh kekhawatiran Mao terhadap kemungkinan pengaruh buruk anasir-anasir Barat tersebut. Mao juga khawatir terhadap kemungkinan pemanfaatan kaum intelektual Cina oleh kekuatan asing/Barat. Sebagian besar kaum intelektual Cina mendapat pendidikan Barat, sehingga menurut Mao, dapat membahayakan posisi dan kekuasaan PKC maupun dirinya. Setelah Cina dianggap bersih atau 'aman', barulah Cina mengundang atau menerima bangsa asing namun tetap dalam pengawasan yang ketat. ${ }^{9}$ Interpretasi di atas menunjukkan bahwa, sentimen anti imperialis, kolonialis, ataupun anti Barat dalam diri Mao, tumbuh bukan semata-mata karena kekejaman yang pernah dilakukan bangsa asing terhadap bangsa Cina. Melainkan karena Mao Zedong takut hal itu akan mengancam eksistensi diri dan kekuasaannya. Menurut Chang dan Halliday, alasan terakhir itulah yang justru menjadi perhatian utama Mao Zedong.

Terlepas dari data kontroversial yang baru terungkap tersebut, dua pedoman kebijakan itu telah mengokohkan keputusan Cina untuk menjalankan kebijakan yi bian dao atau 'bersandar ke satu sisi'. RRC bersandar ke blok sosialis yang saat itu dipayungi oleh kekuatan Uni Sovyet. Pernyataan atau sikap untuk yi bian dao disampaikan Mao Zedong ketika memperingati ulang tahun ke 28 PKC yang antara lain berbunyi seperti berikut.

“一边倒, 是孙中山的四十年经验和共产党的二十八年经验教给我们的, 深知 欲达到胜 利和巩固胜利, 必须一边倒。积累 四十年和二十八年的经验, 中国人不是倒向帝国主义 一边, 就是倒社会主义一边, 绝无例外。骑墙是不行的, 第三条道路是没有的。我 们反对倒向帝国主义一边的将介石反动派，我们也反对第三条道路的幻想.”

\begin{abstract}
"Bersandar ke satu sisi, adalah pelajaran yang diperoleh dari 40 tahun pengalaman Sun Yatsen dan 28 tahun pengalaman PKC, (dari pengalaman itu) diketahui bahwa untuk memdapatkan kemenangan dan mengokohkan kemenangan itu, harus bersandar ke satu sisi. Berlandaskan pengalaman 40 tahun dan 28 tahun tersebut, rakyat Cina tidak bersandar ke pihak Imperialisme, tapi bersandar ke pihak sosialisme, sama sekali tidak ada kekecualian, tidak berpihak (netral) adalah tidak dibenarkan, tidak ada jalan ke tiga. Kita menentang kaum reaksioner Chiang Kai Shek yang berpihak ke Imperialis, kita juga menentang ilusi tentang jalan ketiga."
\end{abstract}

Pernyataan tersebut merupakan penegasan Cina atas sikap anti imperialisme. Meskipun pernyataan itu tidak secara khusus menyebutkan bahwa Cina akan menyandarkan diri atau menaruh harapan untuk mendapatkan perlindungan serta bantuan dari Uni Sovyet, namun arahnya sudah sangat jelas. Hal itu semakin nyata ketika Mao Zedong tak lama setelah proklamasi RRC segera berangkat ke Moskow yaitu pada tanggal 16 Desember 1949. Kunjungan itu sesungguhnya adalah dalam rangka ulang tahun Stalin, namun di dalamnya juga dibicarakan tentang perjanjian persahabatan di

\footnotetext{
9 Jung, Chang, Jon Halliday. Mao: Kisah-Kisah yang Tidak Diketahui. (Martha Wijaya \& Widya Kirana, Penterjemah, (2007), Jakarta: PT Gramedia Pustaka Utama, hlm. 451. 2005.
} 
antara kedua negara. Perjanjian yang disebut Zhong Su youhao tongmeng huzhu tiaoyue atau perjanjian persahabatan, aliansi, dan saling bantu antara Cina dan Uni Sovyet, ditandatangani pada tanggal 14 Februari $1950 .{ }^{10}$ Di dalamnya antara lain disepakati bahwa kedua belah pihak akan saling mendukung, Uni Sovyet akan memberi pinjaman kepada Cina senilai USD 300 juta, dan perjanjian itu akan berlaku selama 30 tahun.

Memperhatikan perkembangan yang melingkupi RRC dan sikap dunia terhadap RRC saat itu, menyebabkan penerapan kebijakan yi bian dao merupakan pilihan rasional bagi Cina, dan bukan sesuatu yang tidak terduga sebelumnya. Kekecewaan Mao Zedong dan para pemimpin, serta rakyat Cina pada umumnya atas sikap dan perlakuan negara-negara Barat terhadap PKC maupun RRC telah membuat Cina sangat anti imperialisme. Hal itu juga telah membuat Cina dikenali sebagai 'kekuatan yang tidak puas' ${ }^{11}$ Contoh peristiwa yang paling nyata mengecewakan Cina saat itu adalah, walaupun RRC telah memproklamirkan kemerdekaannya, ternyata tidak serta merta menjadikannya wakil Cina di forum PBB. Upaya RRC untuk duduk di sana gagal karena Amerika Serikat lebih memilih Republik Cina (Taiwan), untuk mewakili Cina di forum dunia tersebut. AS bahkan membuat RRC semakin terisolasi dari dunia, dengan menerapkan 'politik pembendungan' atau containment policy. ${ }^{12}$ Amerika Serikat juga terus mempropagandakan 'bahaya komunis', yang membuat banyak negara termasuk negara-negara tetangga RRC khususnya di Asia Tenggara mengambil sikap 'menunggu' untuk membuka hubungan dengan RRC. ${ }^{13}$

Di sisi lain, sebagai negara yang baru merdeka dan harus membangun berbagai aspek kehidupan bagi negara dan rakyatnya, RRC juga membutuhkan dukungan finansial. Dukungan itu tak mungkin didapatnya dari negara-negara Barat yang jelasjelas sangat anti komunisme. Uni Sovyet saat itu telah mampu menjadi pesaing bagi Amerika Serikat dan sekutunya. Berlandaskan kesamaan ideologi dan hubungan yang telah terjalin sebelumnya, ${ }^{14}$ Mao dan para pemimpin Cina lainnya menjadikan Uni Sovyet

\footnotetext{
10 “论人民民主专政 (“Pembahasan Kediktatoran Demokrasi Rakyat”), 毛泽东选读 (Karya-karya Terpilih Mao Zedong). (1960)，第四卷 (jilid IV), 北京: 人民出版社 (Beijing: Penerbit Rakyat), hlm. 1477-1478.

11 Choudhury Golam W., (1982), China in World Affairs : The Foreign Policy of the PRC since 1970, Boulder, Colorado : Westview Press, hlm. 18-19.

12 Camilleri Joseph, (1980), Chinese Foreign Policy; The Maoist era $\mathcal{E}$ its aftermath, Seattle University of Washington Press, hlm. 47.

13 Kebijakan Pembendungan (containment policy) diterapkan Amerika pada masa perang dingin untuk membendung penyebaran paham komunis di dunia. Kebijakan ini didasari oleh kepercayaan Amerika Serikat atas kebenaran 'Teori Domino', yang berasumsi bahwa bila satu negara jatuh ke tangan komunis maka itu akan membahayakan negara tetangganya dan kawasan sekitarnya, juga membahayakan Eropa dan Amerika Serikat. Lihat Robet M. Blum, (1982). Drawing The Line: The Origin of The American Containment Policy in East Asia, New York : Norton.
}

${ }^{14}$ Lanteigne, Marc, 2009, Chinese Foreign Policy ; An Introduction, London \& New York : Routledge, hlm.3 
sebagai panutan, dan menganggapnya sebagai model yang harus dipelajari dan ditiru. ${ }^{15}$ Dari sisi strategis Mao juga mengharapkan Uni Sovyet dapat memberikan perlindungan keamanan terhadap Cina. Mao bahkan ingin agar Stalin membantu Cina di bidang pertahanan tidak hanya dengan memberikan senjata, melainkan juga mengajarkan teknologinya. Cina pun berharap USSR bisa membantunya membangun infrastruktur untuk memproduksi senjata, sehingga kelak Cina mampu menjadi kekuatan dunia. ${ }^{16}$

Perang Korea yang meletus pada bulan Juni 1950 turut mempersempit ruang gerak dan pilihan RRC. Alasan keterlibatan RRC dalam perang Korea adalah karena merasa berkewajiban membantu negara tetangga dan Kim Il Sung yang samasama berpaham komunis. Alasan lainnya adalah karena ketegangan di Korea juga mengancam keamanan dan keutuhan wilayah kedaulatan RRC. Landasan kekhawatiran Cina adalah berkaitan dengan tindakan yang dilakukan AS dalam perang itu. Tiga hari setelah pecahnya perang AS telah mendatangkan bantuan militernya ke Korea Selatan, dan mengirim pasukan Armada ke tujuh ke selat Taiwan dengan tujuan mencegah kemungkinan serangan terhadap Taiwan. RRC menganggap Taiwan sebagai bagian dari wilayah kedaulatannya, oleh karena itu masuknya pasukan Amerika Serikat ke wilayah Taiwan merupakan pelanggaran, dan dianggap sebagai tindakan agresi. Mao Zedong segera melakukan protes dan menyerukan agar AS tidak mencampuri urusan dalam negeri orang lain. Zhou Enlai bahkan telah meminta Duta Besar India untuk memperingatkan AS agar tidak melanggar batas garis lintang 38으, namun AS tidak menggubrisnya. Menyikapi perkembangan tersebut, Cina pun kemudian mengirimkan pasukannya dan terlibat langsung dalam perang Korea tersebut. ${ }^{17}$

Keterlibatan Cina dalam perang Korea mendatangkan banyak kerugian yang harus ditanggungnya. Salah satu konsekwensi langsung yang diterima RRC atas keterlibatannya itu adalah terhentinya proses negosiasi pembukaan hubungan diplomatik RRC dengan beberapa negara, termasuk dengan Inggris. ${ }^{18}$ Di sisi lain keterlibatan Cina dalam perang Korea menjadi sebuah tebusan yang sangat mahal, yang harus dibayar Mao dan Cina untuk mendapatkan kepercayaan Stalin. ${ }^{19}$ Awalnya Cina berharap dengan keterlibatannya dalam perang itu akan semakin melicinkan

${ }_{15}$ Uni Sovyet melalui Komintern telah berperan dalam proses berdirinya PKC dan terus mengikuti perkembangan dan membantu PKC walaupun di dalamnya terjadi juga beberapa ketegangan.

16 Abdullah Dahana, (1986), The Evolution of China's Policy Toward Malaysia Since 1949, A Dissertation Submitted to The Graduate Division of The University of Hawaii in Partial Fulfillment of The Requirements for The Degree of Doctor of Philosophy, hlm. 91

${ }^{17}$ Jung, Chang, Jon Halliday, Mao ... Martha Wijaya \& Widya Kirana (Penerjemah), 2007, hlm. 450

${ }_{18} \mathrm{Hu}$ Sheng (Chief Ed,), (1994), A Concise History of The Communist Party of China, Beijing : Foreign Languages Press, hlm. 410-411.

19 “The Downing of New Diplomacy", www.washington.edu/uwpress/search/chapters/LIUCHC.pdf, hlm. $10-11$. 
jalan untuk memperoleh bantuan dan meningkatkan hubungannya dengan USSR. Harapan Cina ternyata meleset, karena bantuan yang dikirimkan USSR tidak seperti yang dijanjikannya. ${ }^{20}$ Kerugian yang harus ditanggung Cina terus berlanjut ke bidang ekonomi. Biaya yang dikeluarkan Cina untuk mengirim pasukan telah membebani anggaran belanja negaranya, sehingga mengganggu jalannya roda perekonomian Cina. Beban ekonomi itu menjadi semakin berat ketika Stalin meninggal pada tahun 1953. Nikita Khrushchev yang terpilih untuk mengantikan Stalin sebagai pemimpin Uni Sovyet ternyata menetapkan kebijakan yang berbeda. Ia menyatakan bahwa, bantuan senjata yang dikirimkan Uni Sovyet untuk digunakan dalam perang Korea tersebut, adalah bagian dari hutang yang harus segera dibayar Cina. Pernyataan itu benar-benar menohok Cina, dan masalah ini kemudian menjadi salah satu sebab retaknya hubungan serta pecahnya aliansi RRC-Uni Sovyet.

\section{PEMBUKAAN HUBUNGAN DAN PENUGASAN WANG RENSHU}

Sempitnya ruang gerak RRC tercermin pada kenyataan bahwa sampai ulang tahun pertama kemerdekaannya baru 17 negara yang menjalin hubungan diplomatik dengannya. Negara-negara itu adalah Uni Soviet, Bulgaria, Rumania, Hungaria, Korea, Czechoslovakia, Polandia, Mongolia, Jerman, Albania, Burma, India, Vietnam, Denmark, Swedia, Swiss, dan Indonesia. ${ }^{21}$ Perdana Menteri Indonesia Mohammad Hatta mengirimkan kawat yang berisi keinginan untuk menjalin hubungan diplomatik dengan RRC pada tanggal 15 Januari 1950. Mao Zedong yang saat itu sedang melakukan kunjungan kenegaraan ke Moskow, pada tanggal 26 Januari 1950 mengirimkan kawat kepada Liu Shaoqi sebagai Ketua negara ad interim agar mempersiapkan pembukaan hubungan tersebut. ${ }^{22}$ Meskipun demikian jawaban kepada Indonesia tidak segera dikirimkan. Zhou Enlai yang saat itu menjabat sebagai perdana menteri merangkap menteri luar negeri, baru mengirimkan kawat jawaban kepada Hatta pada tanggal 28 Maret 1950. Lambatnya pengiriman jawaban itu tampaknya disebabkan oleh adanya keraguan RRC terhadap Indonesia.

Keraguan RRC terutama disebabkan oleh masih adanya tujuh konsulat Republik Cina (Taiwan) di Indonesia. RRC menduga Indonesia akan menjalankan kebijakan dua Cina, di sisi lain RRC saat itu masih menganggap Indonesia sebagai bagian dari kekuatan pro Barat. Keberadaan tujuh konsulat itu merupakan bagian dari hubungan

\footnotetext{
${ }^{20}$ Hsu, Immanuel C Y, (1990), The Rise of Modern China, New York, Oxford University Press, hlm. 675.

${ }^{21}$ Dalam buku Hu Sheng, (1994), A Concise History of... digambarkan bahwa Uni Sovyet di saat-saat terakhir ternyata tidak mengirimkan pasukan udara yang dijanjikannya untuk mendukung pasukan RRC dalam perang tersebut, hlm. 415.

${ }^{22}$ Zhou Enlai, "Chinese People Will not Tolerate Aggression", World News and Views, Vol. 30, No. 41 (October 14, 1950), Pidato pada peringatan hari Kemerdekaan Republik Rakyat Cina yang pertama, http://www. marxists.org/reference/archive/zhou-enlai/1950/10/x01.htm.
} 
pemerintahan kolonial Belanda dengan Republik Cina di masa lalu. Pemerintah RI tidak menjalin hubungan diplomatik dengan Republik Cina, bahkan RI tidak menanggapi surat pengakuan kedaulatan yang dikirimkan Republik Cina pada tanggal 27 Desember 1949. Pada saat itu pemerintahan Republik Cina sedang dalam proses kepindahan ke Taiwan. Menurut Mozingo, sebenarnya ketika Hatta mengirim kawat untuk menjalin hubungan diplomatik dengan RRC, Hatta juga mengirim nota kepada perwakilan Taiwan untuk segera menutup konsulatnya di Indonesia. Hal itu menunjukkan bahwa tidak ada maksud Indonesia untuk mengakui atau menjalin hubungan diplomatik dengan dua pemerintahan Cina. ${ }^{23}$ Fakta-fakta di atas menghapus keraguan RRC dan segera dikirimkanlah kawat yang menyatakan pengakuan RRC terhadap kedaulatan Republik Indonesia. Hatta kemudian menjawab kawat RRC tersebut pada tanggal 13 April 1950, maka sejak saat itu secara resmi telah terjalin hubungan diplomatik Cina- Indonesia.

Kedua belah pihak sudah saling mengakui kedaulatan masing-masing, namun hubungan yang lebih definitif dan kongkrit tidak segera berjalan. Pada bulan Mei 1950 pemerintah RRC melanjutkan proses hubungan itu dengan menetapkan Wang Renshu sebagai Duta Besar. Berbeda dengan RRC yang segera mengirimkan duta besarnya, Jakarta baru mengirim Isak Mahdi sebagai kuasa usaha pada bulan Januari 1951. Tertunda dan tidak setaranya tingkat perwakilan yang dikirim Indonesia ke Cina, adalah disebabkan oleh masih adanya keberatan dari sejumlah pihak di Indonesia atas pembukaan hubungan diplomatik RI-RRC. Keberatan yang berkaitan dengan ideologi komunis yang dianut RRC itu terutama datang dari para tokoh Islam dan sejumlah tokoh masyarakat lainnya. Mereka belum bisa melupakan peristiwa Madiun tahun 1948 yang digerakkan oleh Partai Komunis Indonesia (PKI). Tokoh-Tokoh itu khawatir kehadiran perwakilan RRC di Indonesia selain akan membesarkan PKI juga akan membangkitkan simpati kaum Tionghoa terhadap nasionalime Cina. ${ }^{24}$

Sikap antusias RRC tampaknya juga dipicu oleh kesadaran atas adanya potensi nyata yang ada di Indonesia yang dapat bermanfaat baginya, yaitu kaum Tionghoa. Jika RRC mampu mempengaruhi kaum Tionghoa, maka akan memberi keuntungan ganda. Di satu sisi dapat 'memukul' Taiwan, dan di sisi lain bisa mendapatkan dukungan finansial dari kaum Tionghoa. Keberhasilan misi itu akan meningkatkan kewibawaan dan prestise RRC, baik secara internasional (karena merebut pengaruh dari Taiwan), maupun di hadapan kaum Tionghoa itu sendiri. Penunjukan Wang Renshu sebagai duta besar pertama RRC untuk Jakarta tampaknya juga berkaitan dengan adanya potensi yang harus dimanfaatkan tersebut.

\footnotetext{
${ }_{23}$ File no. 105-00003-07, Archives of the Ministry of Foreign Affairs, PRC. Dikutip dari Hong Liu, (2011), China and the Shaping of Indonesia, 1949-1965, Singapore : NUS Press in association with Kyoto University Press, Japan, hlm. 175

${ }^{24}$ Mozingo, David, (2007), Chinese Policy Toward Indonesia 1949-1967, Jakarta, Kuala Lumpur : Equinox Publishing, hlm. 89
} 
Kementerian Luar Negeri RRC dibentuk pada 8 November 1949. Sejalan dengan pedoman bahwa 'RRC tidak mewarisi pemerintahan Guomindang' maka struktur maupun personil dari institusi ini pun merupakan bentukan baru. Saat itu tidak banyak kader PKC yang berpengetahuan atau perpengalaman dalam hal hubungan luar negeri. Zhou Enlai hanya bisa mengandalkan sumber daya manusia dari veteran perang, perwira militer, dan lulusan studi bahasa asing dari universitas, untuk ditempatkan sebagai diplomat di luar negeri. Wang Renshu alias Ba Ren lahir di propinsi Zheqiang pada tahun 1900. Profesinya adalah sebagai seorang guru dan penulis. Wang telah bergabung dengan PKC sejak tahun 1924. Pada saat pecahnya perang Pacifik ia berangkat ke Indonesia dan tinggal di Sumatera hingga tahun 1948. Selama di Indonesia Wang ikut aktif dalam gerakan kemerdekaan Indonesia dan bidang pendidikan, di kalangan masyarakat Indonesia ia dikenal dengan sebutan "Pak Bahren". ${ }^{25}$ Latar belakang, pengalaman, dan kemampuan berbahasa Indonesia yang dimiliki Wang merupakan alasan yang paling tepat untuk penunjukkannya sebagai Duta Besar RRC untuk Indonesia. Terutama bila dikaitkan dengan salah satu tujuan RRC agar perwakilannya mampu memanfaatkan potensi yang dimiliki kaum Tionghoa untuk kepentingan pembangunan RRC.

\section{MANUVER WANG RENSHU DAN SIKAP INDONESIA}

Wang tiba di Jakarta pada bulan Juli 1950 dan menyerahkan surat-surat kepercayaan kepada Presiden Soekarno pada bulan Agustus. Sejak kedatangannya Wang secara agresif berupaya mendekati kaum Tionghoa yang ada di Indonesia. 'Senjata' yang digunakannya untuk melakukan hal itu adalah pasal 37 dan 58 Program Umum ${ }^{26}$ atau UUD RRC. Isi pokok pasal-pasal itu menetapkan bahwa, seluruh keturunan Cina yang berada di luar negeri adalah warga negara RRC, dan pemerintah RRC wajib memberi perlindungan terhadap keselamatan diri dan aset mereka. Pada bulan Oktober Wang menyampaikan keinginan RRC untuk membuka kembali tujuh konsulat yang ditinggalkan Taiwan. Menurutnya ketujuh konsulat itu perlu segera dibuka kembali agar pemerintah RRC dapat melayani kepentingan kaum Tionghoa yang juga merupakan warga negaranya.

Pemerintah Indonesia tidak dapat menerima keinginan itu. Alasan Indonesia, pertama karena RRC berbeda dengan Taiwan, artinya RRC tidak bisa secara otomatis

\footnotetext{
25 "The Downing of New Diplomacy", www.washington.edu/uwpress/search/chapters/LIUCHC.pdf, hlm. 11-17; Hong Liu, (2011), China and the Shaping of ..., hlm. 175.

${ }^{26}$ Program Umum adalah terjemahan dari Common Program yang menunjuk kepada dokumen 中国人 民政治协会议 共同纲领 (Zhongguo Renmin Zhengzhi Xiehuiyi Gongtong Gangling; Program Bersama Konferensi Permusyawaratan Politik Cina). Dokumen ini ditetapkan sebagai ‘Undang-Undang Dasar/ UUD' sementara RRC pada 29 September 1949. UUD RRC ini mengalami beberapa kali perubahan atau diamandemen, di antaranya pada tahun 1954, 1977, 1982, dan 1999. (Mozingo, David, (2007), Chinese Policy..., hlm. 90-91 ; Abdullah Dahana, (1986), The Evolution of China's Policy Toward Malaysia Since 1949, A Dissertation Submitted to The Graduate Division of The University of Hawaii in Partial Fulfillment of The Requirements for The Degree of Doctor of Philosophy in History, hlm. 65).
} 
mengambil alih aset yang ditinggalkan Taiwan. Ke dua, pembukaan tujuh konsulat sekaligus di tahap yang masih sangat awal adalah tidak rasional. Ke tiga, menurut ketetapan Konferensi Meja Bundar (KMB), keturunan Cina yang lahir di Indonesia dalam dua tahun terhitung sejak tanggal 27 Desember 1949, akan menjadi warga negara Indonesia, kecuali bila yang bersangkutan secara resmi memilih atau telah menjadi warga negara lain. ${ }^{27}$ Khusus berkaitan dengan alasan ke tiga tersebut, maka Indonesia menganggap masalah kewarganegaraan kaum Tionghoa baru relevan untuk dibicarakan setelah Desember 1951. Menanggapi alasan Indonesia tersebut, Wang menyatakan bahwa, sesuai dengan UUD RRC kaum Tionghoa adalah warga negara RRC. Dengan demikian bila mereka ingin mengubah kewarganegaraannya maka mereka harus mendapatkan surat keterangan dari pemerintah RRC, karena itulah dibutuhkan konsulat-konsulat tersebut agar memudahkan mereka. ${ }^{28}$

Perundingan tentang hal itu berlangsung alot, hingga akhirnya pada bulan Maret 1951 Indonesia mengizinkan RRC untuk membuka konsulatnya di empat kota besar yang mewakili pulau-pulau besar di Indonesia. Keempat konsulat itu adalah di Jakarta untuk pulau Jawa, Medan untuk pulau Sumatera, Banjarmasin untuk Kalimantan, dan Makasar untuk pulau Sulawesi. Hanya dalam waktu sekitar satu tahun, Wang Renshu dan koleganya berhasil menarik sekitar 600 - 700 ribu orang kaum Tionghoa untuk menjadi warga negara RRC dan menolak kewarganegaraan Indonesia. Jumlah itu cukup besar karena merupakan 40\% dari seluruh kaum Tionghoa yang saat itu berada di Indonesia. Pemerintah Indonesia mulai merasa gerah atas manuver-manuver Wang tersebut. Sebaliknya, langkah Wang untuk menarik kaum Tionghoa tidak berhenti di sana. Kemampuannya berbahasa Indonesia membuatnya mudah diterima di lingkungan kaum Tionghoa, maupun masyarakat Indonesia lainnya. Beralihnya orientasi Bank of China yang semula ke Taiwan menjadi ke RRC, adalah keberhasilan Wang lainnya yang sangat berarti bagi RRC.

Sepak terjang Wang itu semakin meresahkan pemerintah Indonesia. Sebagai bentuk protes, pada bulan Juli 1951 Indonesia menolak kedatangan 16 dari 20 orang staf kedutaan RRC yang semula akan ditempatkan di Indonesia. Menurut Indonesia hal itu dilakukan karena RRC tidak membuat pemberitahuan terlebih dahulu, meskipun Indonesia telah mengingatkannya. Beijing memprotes tindakan Indonesia tersebut karena alasan Indonesia itu dianggap tidak rasional, mengingat bahwa ke 16 orang tersebut telah mendapatkan visa untuk masuk ke Indonesia. ${ }^{29}$ Meskipun demikian Indonesia tidak menarik keputusannya. Bagi Indonesia, banyaknya staf di kedutaan besar RRC akan menyulitkan Indonesia untuk melakukan pengawasan. Terlebih telah

\footnotetext{
${ }^{27}$ Suryadinata, Leo. Dilema Minoritas Tionghoa. Jakarta: Grafiti Press, hlm. 117. 1984.

${ }^{28}$ Mozingo, David. Chinese Policy ..., hlm. 93. 2007.

${ }^{29}$ Mozingo, David, (2007), Chinese Policy ..., hlm. 99.
} 
terbukti upaya-upaya RRC dalam membujuk kaum Tionghoa untuk berafiliasi ke RRC. Indonesia bahkan kemudian mem-persona non grata-kan Wang Renshu, berkaitan dengan kegiatan provokasi anti Amerika yang dilakukannya. ${ }^{30}$

Tindakan Indonesia menyadarkan RRC bahwa, bila diteruskan langkahlangkah Wang tersebut akan membahayakan hubungan kedua negara dan merugikan RRC. Bagaimana pun saat itu RRC masih membutuhkan Indonesia. Bukan hanya karena keberadaan kaum Tionghoanya saja, tapi juga karena posisi strategis Indonesia khususnya berkaitan dengan persaingan antara kekuatan sosialis dan imperialis. Strategisnya posisi Indonesia dalam persaingan di antara dua kubu itu adalah karena Indonesia menerapkan politik luar negeri 'bebas aktif' yang membuat Indonesia tidak mau terikat oleh kekuatan manapun. Sikap itu ternyata telah membuat Indonesia mempunyai posisi tawar tinggi dalam pergaulan antar bangsa di dunia. Menlu Amerika Serikat saat itu Dean Acheson menyatakan bahwa. "mempertahankan Indonesia sebagai kekuatan anti komunis semakin lama semakin penting". Di tengah upaya AS yang semakin gencar dalam mengisolasi RRC, memburuknya hubungan dengan Indonesia tentu akan semakin menyulitkan gerak RRC di dunia.

Bila RRC membiarkan Wang Renshu melanjutkan manuver-manuvernya akan memungkinkan Indonesia melakukan tindakan yang lebih keras lagi, misalnya memutuskan hubungan dengan RRC. Lepasnya kepercayaan Indonesia akan mempengaruhi pandangan bangsa-bangsa di Asia Tenggara terhadap RRC dan membuat RRC kehilangan pamor di dunia. Bila hal itu terjadi maka akan membuatnya semakin sulit untuk keluar dari politik pembendungan AS. Selain itu juga akan membuat RRC kehilangan kepercayaan dan dukungan dari kaum Tionghoa dan bahkan mungkin dari kaum Huaqiao ${ }^{31}$ di wilayah-wilayah lainnya di dunia. Berlandaskan kalkulasi itu maka untuk menghindari terjadinya kerugian lebih lanjut, pada akhir tahun 1951 RRC menarik pulang Dubes Wang Renshu. Keputusan RRC itu tidak hanya telah menyelamatkan hubungannya dengan Indonesia, tapi juga merupakan langkah awal ke arah hubungan yang lebih baik di antara kedua negara.

\section{KESIMPULAN DAN PENUTUP}

Manuver-manuver Wang Renshu yang terurai di atas sudah pasti berkaitan erat dengan kebijakan dan target politik luar negeri RRC. Saat itu RRC secara internal sedang membutuhkan dukungan finansial untuk membangun negerinya, dan RRC melihat peluang itu dalam komunitas kaum Tionghoa di Indonesia. Secara eksternal RRC membutuhkan dukungan politik untuk memperkuat eksistensi internasionalnya,

\footnotetext{
${ }^{30}$ Hong Liu, (2011), China and The Shaping of ...., hlm. 176.

${ }^{31}$ Sebutan Huaqiao digunakan untuk menunjuk para perantau Cina yang ada di berbagai negara di dunia, sedang sebutan Tionghoa adalah untuk menunjuk keturunan Cina yang ada di Indonesia.
} 
dan RRC melihat hubungan yang baik dengan Indonesia dapat memberi peluang besar untuk itu. Kapasitas Wang sebagai kader PKC yang telah terbina sejak tahun 1924, ditambah dengan kedekatannya dengan masyarakat Indonesia sebenarnya memang sangat tepat untuk mewakili RRC di Jakarta. Sayangnya Wang melakukannya dengan sangat bersemangat dan lebih mengutamakan kehendaknya sendiri. Perilaku Wang tampak sangat sejalan dengan pemikiran dan gaya Mao Zedong yang dikenal sangat militan dan mengutamakan nasionalisme Cina. Langkah-langkahnya untuk mendapatkan dukungan kaum Tionghoa sangat tidak diplomatis, sehingga membuat Indonesia tidak nyaman dan bahkan 'tersinggung'. Terutama ketika Wang secara agresif melakukan provokasi anti Amerika dan bahkan mengkritik pemerintahan Soekarno. Tentang langkah-langkahnya itu Wang sendiri kemudian mengakuinya sebagai sikap "kurang disiplin dan mengabaikan aturan protokoler" sehingga Ia sering mendapat teguran dari Menlu RRC. ${ }^{32}$

Wang Renshu boleh saja pada akhirnya menyesali semua kesalahan yang telah dilakukannya, namun kasusnya tetap tercatat sebagai sebuah kegagalan dalam sejarah diplomasi RRC. Dalam studi hubungan internasional secara umum diplomasi diartikan sebagai tindakan atau upaya cerdik suatu negara atau perwakilannya untuk mempengaruhi pandangan negara lain agar sejalan dengan kepentingan nasional negaranya. Berlandaskan pemahaman itu maka terlihat bahwa manuver-manuver Wang Renshu tidak cukup cerdik dan etis, karena lebih menonjolkan militanisme dan nasionalismenya. Dalam hal ini cara yang digunakan Wang cenderung memaksakan kehendak daripada kompromi. Beruntung RRC cepat menyadari kesalahan yang dilakukan Wang dan segera menariknya pulang. RRC kemudian mengirim Huang Zhen sebagai penggantinya, dan Indonesia pun mengirim Arnold Mononutu sebagai Duta Besar pertamanya untuk Beijing. Sejak itu hubungan kedua negara berlangsung dalam pasang surut yang sangat dinamis hingga terjadinya pembekuan hubungan pada tahun 1967.

\section{DAFTAR PUSTAKA}

Camilleri, Joseph. Chinese Foreign Policy; The Maoist era \& its aftermath, Seattle University of Washington Press. 1980.

Chesneaux, et. al. China From The 1911 Revolution To Liberation, New York: Pantheon Books. 1977.

Chen, Yi. 2002. "Stands Guard on the Bund" dalam Shanghai Star. (31 October 2002).

Choudhury, Golam W. China in World Affairs: The Foreign Policy of the PRC since 1970, Boulder, Colorado: Westview Press. 1982.

${ }^{32}$ Hong Liu, (2001), China and The Shaping of ..., hlm. 176 
Dahana, Abdullah. The Evolution of China's Policy Toward Malaysia Since 1949. A Dissertation Submitted to The Graduate Division of The University of Hawaii in Partial Fulfillment of The Requirements for The Degree of Doctor of Philosophy. 1986.

Hong, Liu. China and the Shaping of Indonesia, 1949-1965. Singapore: NUS Press in association with Kyoto University Press, Japan. 2011.

Huang, Anyu (黄安余). 新中国外交史 'Sejarah Diplomasi Cina Baru'. Beijing: 人民出版 社 (Penerbit Rakyat). 2005.

Jung, Chang dan Jon Halliday. Mao: Kisah-Kisah yang Tidak Diketahui, diterjemahkan oleh Martha Wijaya dan Widya Kirana, 2007. Jakarta: PT Gramedia Pustaka Utama. 2005.

$\mathrm{Hu}$ Sheng (ed.). A Concise History of The Communist Party of Chin. Beijing: Foreign Languages Press. 1994.

Hsu, Immanuel C. Y. The Rise of Modern China. New York, Oxford: Oxford University Press. 1990.

Kong, Yuanzhi. Silang Budaya Tingkok-Indonesia. Diterjemahkan oleh Xie Zhiqiong, Kong Yuanzhi, Xie Yinghua. Jakarta: PT. Buana Ilmu Populer. 2005.

Lanteigne, Marc. Chinese Foreign Policy: An Introduction. London \& New York: Routledge. 2009.

论人民民主专政 'Pembahasan Kediktatoran Demokrasi Rakyat' dalam 毛泽东选读 'Karya-karya Terpilih Mao Zedong'. 第四卷, jilid IV, 北京: 人民出版社 (Beijing: Penerbit Rakyat). 1960.

Mozingo, David. Chinese Policy Toward Indonesia 1949-1967. Jakarta, Kuala Lumpur: Equinox Publishing. 2007.

Robert, M. Blum. Drawing The Line: The Origin of The American Containment Policy in East Asia, New York: Norton. 1982.

Suryadinata, Leo. Dilema Minoritas Tionghoa. Jakarta:Grafiti Press. 1984.

Walker, Richard. China Under Communism. New Heaven: Yale University Press. 1955.

Zhao, Quansheng. Interpreting Chinese Foreign Policy; The Micro-Macro Linkage Approach. Oxford, New York : Oxford University Press. 1996.

\section{INTERNET}

Zhou, Enlai, "Chinese People Will not Tolerate Aggression”, World News and Views, Vol. 30, No. 41 (October 14, 1950). Pidato pada peringatan hari Kemerdekaan Republik Rakyat Cina yang pertama, http://www.marxists.org/reference/archive/zhouenlai/1950/10/x01.htm, diunduh pada 12 Januari 2011, pukul 22.00.

"The Downing of New Diplomacy", www.washington.edu/uwpress/search/ chapters/LIUCHC.pdf, diunduh pada 24 Juli 2010, pukul 11.00. 